presenting naturally; it was most frequently found that one child presented naturally by the vertex, whilst the other presented by the breech or the foot. The longest period which he recollected to have intervened between the birth of each child was fourteen hours. In that case the presentation of the second child was a natural one, but there was a total absence of uterine pain.

Mr. SNow stated that his experience, respecting the varied presentations in twin cases, coincided with that of Mr. Dumn. He remembered attending one case of twins in which one child presented by the shoulder, and the other by the knec.

Mr. Streeter said that, in the practice of $\mathrm{Dr}$. Collins and Dr. Ramsbotham, the majority of the children presented naturally; there were, howeves, occasional and frequent variations to this rule.

\section{January 29.}

LITHOTRIPSY.

Mr. Bнооке brought forward a paper on lithotripsy. He began by observing, that he should confine himself to such observations as had a practical bearing upon the subject. 'The aceessory apparatus necessary to the performance of the operation consisted of a recto-curvilinear sound, having a curve proportioned to the age of the patient, by which the bladder was explored, and the nature of the foreign body ascertained. A certain degree of rapidity was required in passing this instrument, in order to avoid urethral spasm. He (Mr. Brooke) was accustomed to use a circular sounding board, which was fixed to the sound when it had entered the bladder, and by this means the sonorous vibrations between the sound and the stone in the bladder were more correctly ascertained; vibrations of sound would travel longitudinally, and these would further detect the difference between the relative texture and density of the stone, as well as the smoothness or roughness of its surface, and whether of the lithic acid or mulberry species. The rectangular bed of Heurteloup could be packed up in a small space, and its head could be lowered at pleasure, to enable the operator to reach the bas fond of the bladder. This method he considered preferable to the plan of forcibly depressing the sound when in the bladder, which caused the patient considerable pain, from straining the dorsal ligament of the penis and neck of the bladder. The mechanical means ployed to destroy the stone were attrition, pressure, and percussion. In the earliest days of lithotripsy, chemical solvents were used in connection with the operation. Attrition was a means now seldom resorted to in the destruction of calculi, as it was only applicable to the smaller kinds, and was inferior to pressure. In employing attrition upon flat stones, he had frequently found that the drill got into the same hole, by which the operation was prolonged and yet no progress made in it. He drew the attention of the members present to an improvement in the drill of the three branched instrument, by which it might be so withdrawn within the tube as to avoid drawing in any fold of the mucous lining of the bladder.

Pressure was employed by a curved instrument having two sliding branches. He objected to pressure, considering it dangerous, unsafe, and highly objectionable; and in employing it he had heard of cases in which the instrument had been broken in the bladder. The stone was less broken, and the dispersion of the fragments more violent. All vesical calculi were more or less laminated in their texture, and by employing percussion to destroy them, their texture was more thoroughly disintegrated than by other means. 'The quality of the stone was easier detected, and there was no violent dispersion of the fragments; repeated small blows of the hammer were more useful than one large one. The objections which had been raised against the shock which percussion caused to the patient were perfectly groundless, as, if the instrument were properly placed, the vibration of the blow being longitudinal, neither the bladder nor the urethra could feel the jar. In making the instruments for lithotripsy, it was necessary that they should possess a certain amount of strength, and he had found by experiment that cast steel, hardened at the lowest temperature, gave the strongest instrument. In proving the metal some allowance should be made for the set of the instrument. If these facts were closely attended to, there would be no fear of the instrument breaking. In seizing the stone, the posterior branch of the instrument should be depressed on the inferior surface of the bladder, and by using gentle agitation, the stone soon falls in between the branches. If from astlima, or a determination to cerebral affection, the patient could not be lowered, it might be necessary to use the instrument in a lateral direction. The stone, when seized, should be placed in a safe position in the bladder, and the instrument drawn forwards for a certain space; this would determine the depth of the bladder from before backwards; the instrument should then be returned back to a medium distance between these two points, and the stone would then be in the centre of the fluid contents of the bladder, and this method should be adopted in crushing every single calculous fragment. In using percussion every succecding shock should be increased in strength, and the broken fragments removed by the spoon catheter of Heurteloup, which had a hollow in each branch. In common cases the action of the bladder alone was sufficient to remove all the fragments; but in cases where from paralysis of the bladder, or diseased prostate gland, this was in sufficient, the spoon instrument was very useful; or the evacuating sound (having a large eye and a jointed stiletto) might be used to inject the bladder. If a calculous fragment should lodge in the eye of the instrument, it should be removed by introducing the stiletto, and pushing the small calculus into the upper chamber of the instrument, and crushing it. If a fragment of stone lodged at the neck of the bladder, anterior to the triangular ligament, it should be removed by a small pair of forceps, invented by i'rofessor Fergusson; or if it were posterior to the triangular ligament, it should be pushed back into the bladder; if spasm occurred at this time, it would bo best obviated by making the patient pass water. Rigors sometimes occurred after the introduction of instruments in these cases; but Baron Heurteloup has laid it down as a lithotriptic axiom, that rigors never occurred after the stone had been broken. Cases sometimes happened, as in children, where the patient could not refrain from making powerful muscular efforts, by which the fluid was thrown into the upper part of the bladder, and the operation rendered more difficult of performance. A diseased and rugose state of the membrane of the bladder, or an increase of its muscular coats, by which the mucous lining was thrown into small sacculated pouches, in one of which a calculus might be imbedded-such a state of facts as this would render this operation, as well as lithotomy itself, a diffcult one to perform. Some steps of the operation were then demonstrated, but in a very imperfect manner, and the time of the meeting having expired, the discussion was, on the motion of Mr. Alcock, adjourned.

\section{ROYAL BERKSHIRE HOSPITAL.}

[Practice of Mr. F. A. Bulley.]

PAINFUL SWELLING OF THE BREAST, APPARENTLY DETENDING ON IRREGULARITY OF THE CATAMENIAL DISCHARGE.-NEURALGIA.

M. A. Holloway, housemaid, aged 23, was admitted into the Royal Berkshire IIospital, September 2, on account of a painful enlargement of the left breast, which she said had existed for about six weeks. 
There was no external redness, nor any indication of the presence of matter in any part of its structure. It was, however, extremely tender to the touch, the tenderness extending superficially up the neck on the same side as far as the mastoid process, about which part there was a slight blush of redness. She could give no exact account of the origin of her complaint, farther than that, about six weeks before admission, she began to feel dull pains in the breast, and observed the progress of a soft and uniform enlargement of the gland $s$ lier liealth also became disordered, and, from being in a state of tolerable health before, she became nervous and irritable, occasionally affected with shiverings and flushes after taking food, sickness, with loss of appetite, and feeling of great depression and fatigue after very slight exertion. She also became affected with hysterical sensations to which she had not been particularly liable before. The catamenia had been scanty and irregular in thcir appearance for some time. 'The general and local symptoms had continued to increase until she found she was obliged to give up her work entirely. She now appears extremely nervous, and hats all the signs of disordered health which I hive mentioned. Thinking her complaint to be simply local neuralyia, depending on uterine disturbance, I prescribed for her the following plaster, which I have found serviceable in similar cases, to be spread on soft leather, and applied over the affected breast and side of the neck, with such medicines as I thought best calculated to allay the general febrile condition of her system, and enjoined the most minute attention to diet :-

Camphor, one scruple;

Extract of hops, one drachm and a half ;

spermaceti, cnough to make a plaster. 'To be spread on soft linen, and applied over the affected parts.

Tincture of hyosciamus, one drachm and a half ;

Saline mixture, eight ounces. Three tablespoonfuls thrice a day.

A warm hip bath every alternate day; middle diet; with half a pint of weak cold brandy and water daily.

24. By pursuing the simple means I have described, she has daily continued to improve in health. The pain and swelling in the breast have entirely left her, bus she still occasionally feels shooting sensations in the neck, with some tenderness on pressure. Sometimes also she feels rather sick, and her head aches, especially in the morning; the catamenia have appeared with no considerable deviation from the healthy function, and unaccompanied by pain; pulse still feeble but regular. She says that she always suffered great pain in the spine and loins about the catamenial period, and especially just before admission, when she described it as a hot pain continually shooting down the spinal marrow. The constant application of the plaster has brought out a copious and very irritable herpetic eruption, to which it is necessary to apply a bread and water poultice, and afterwards lotio plumbi.

27 . The deep seated pains of the breast and neck are quite gone; an eruption of the same kind as was produced by the plaster has spread over the cheek of the same side, and the eyelid is tumid and drooping ; slight appearances of erysipelas. Hot water in a sponge to be constantly applied to the face. To take house medicine.

29. The slight blush of erysipelas has disappeared, leaving a trifling effusion of the eyclid; to repeat the house medicine.

Oct. 1. Her general health is now quite restored, and the swelling of the breast and the pains in the neck have disappeared; a slight itching on the surface alone remains. Her appetite not having completely returned, I ordered-

Carbonate of soda, fifty grains;

Infusion of Cascarilla, twelve ounces. A tableyoonfu. twice a day.
6. Discharged from the hospital apparently quite cured.

Although the preceding case resembled in some degree, the irritable breast so well described by the late Sir Astley Cooper, it differed from it in so many respects, as to make it probable it was not at all of that character. The somewhat sudden appearance of the complaint; the absence of pain, or any particular indication of discase of the part, during previous catamenial periods ; the enlargement, apparently from severe effusion of the subcutancous and interstitial textures of the gland, which not unfrequently accompanies neuralgic affections in other parts, render it not unlikely that it was a purely neuralgic affectionthe sympathetic result of the disturbed catamenial function, which again might either be the cause or the effect of the disturbance of the general health.

SEVERE SCALD FROM MELTING PITCH, CURED BX THE APPLICATION OF TREACLE AND WATER AS A LOTION.

George 'Tull, a bargeman's boy, aged 13, was admitted into the hospital, July 4, 1841. He had been employed by his master in pitching the sides of an old coal barge, when, by some accident, the cauldron containing the melted pitch was overturned, the contents of it being poured upon the foot and ancle of the boy who was standing near it at the time. On his arrival at the hospital, it was found that the pitch, having become cool, had formed a caking over the scalded part, so that it was difficult, if not impossible to detach it, so as to ascertain the exact extent of the injury. In a day or two afterwards, however, the nurse succeeded in removing it, when it was found that the integument covering the foot and ancle had becin destroyed, although the cellular membrane and parts immediately underneath appeared to have been unaffected. The detachment of the pitch showed that granulations had already begun to form on the exposed surface of the wound. He had no particular febrile disturbance following the injury, and had previously enjoyed excellent health.

July 6 . The surface of the scalded parts being now fully exposed by the removal of the pitch, the foot was covered with a paste composed of equal parts of treacle and flour, with a view to prevent any injurious effects which might arise from the access of air to the denuded surface.

16. The caking of flour and treacle, which had been from time to time thickened by fresh supplies of each ingredicnt, was removed. 'The surface is covered with healthy florid granulations. As it was thought that the paste prevented in some measure the cicatrisation from the margin, and obscured the disease, it was discontinued, and instead of it a lotion composed of cqual parts of treacle and water, was ordered to be kept constantly applied to the parts. He was placed on middle diet.

Scpt. 7. The surface of the scalded parts has become almost entirely healed, without any appearance of seam or contraction in the cicatrix. A number of boils have appeared on the neighbouring integument of the leg, which $I$ attribute to his having been on extra diet, with porter, without using proper exercise. Discontinuing this, the boils rapidly disappeared. A lotion containing chlorate of lime, in solution, was ordered to be used to the unhealed parts.

28. The scalded foot, although now quite healed, has a red tettery appearance. The acetate of lead cerate to be applied twice a day. The change of diet seems to have had a beneficial effect in completing the cicatrisation; has been lately using the hot water pump to the foot, with some apparent advantage. The joint is somewhat stiff, although there is no appearance of contraction of the cicatrix.

Oct. 4. The appearance of the foot, and the movement of the ancle-joint, have become greatly improved during the last few days, owing, he thinks, to the unremitted use of the hot pump. The whole cicatrix 
has a healthy smooth appearance, without seam or puckering of any kind; and, as he was able to move the joint freely, and walk about the garden with tolerable case, he was discharged from the hospital, and made an out-patient.

He called a short time afterwards and told me that he walked with perfect freedom, and had had no retum of ulceration of the cicatrix, as is sometimes found to be the case after injuries of this kind.

In recording the treatment adopted in the foregoing case, I do not wish to take any credit to myself for employing a remedy with the virtues of which, in such cases, surgeons have been long acquainted. $\mathrm{Mr}$. Greenhow, of Newcastle, first introduced it into practice, using it as a defensative, for the purpose of preventing the access of air to the denuded parts. He did not, I believe, continue to use it thronghout the whole progress of the case, but substituted for it other applications which the circumstances of the case might afterwards seem to require. In the commencement of the preceding case I used it, mixed with flour, for the same purpose of excluding air, but, finding it occasioned pain, and that I could not properly see what was going on underneath, although it had seemed to promote the growth of granulation, I determined to use equal parts of treacle and water, on rags, constantly applied as a lotion to the injured surface. The application of treacle in this manner has convinced me by the result of this, and other cases similarly treated, that it has some specific effect in expediting the cicatrisation of burns and scalds, however extensive they may be, and that it prevents, in a great degree, the unsightly puckering and contraction which too often interfere with the proper actions of joints involved in these accidents. I have, since that time, had several opportunities of testing its value as a remedy in these cases; and have, from what $I$ have seen of its effects, adopted it in every case of the kind which has come under my care, both in hospital and private practice; and in each case it has seemed to have been instrumental in preventing, or at least diminishing, the chances of consecutive contraction.

\section{KING'S COLIEGE HOSPITAL.}

EXCISION OF THF SUPERIOR MAXILLARY BONE.

On Wednesday last Mr. Fergusson excised the superior maxillary bone, before a numerous collection of students, and members of the profession, from different parts of the metropolis. We had the advantage of being present during the performance of this difficult operation, and cannot avoid expressing our admiration of the coolness and dexterity which Mr. Fergusson displayed on this occasion. The patient was a child about 12 years old, affected with a tumour of the superior maxillary bone; the tumour had grown very slowly, and presented several characters, which induced Mr. Fergusson to believe that it was not of a malignant nature. The result of the operation proved the correctness of Mr. Fergusson's diagnosis. The morbid growth was composed of bone, and fibrocartilage : the whole of the diseased parts were removed, and we sincerely trust that the ultimate result of the operation, which cannot fail to increase Mr. Fergusson's reputation in a remarkable degree, will be favourable.

\section{POOR-LAW MEDICAL RELIEF.}

We have been favoured by the President of the Royal College of Surgeons with the following communication on the subject of poor-law medical relief. Although we cannot agree with $\mathrm{Mr}$. Guthrie in expecting any considerable ameliorations from the poor-law commissioners, we camnot but return our thanks, on the part of the medical profession, to Mr. Guthrie, for the praiseworthy exertions, which we have reason to know he has recently made on the behalf of union surgeons :-$$
\text { “ } 4 \text {, Berkeley-street }
$$$$
\text { Feb. 1, } 1842 .
$$

My dear Sir,-I am glad to have it in my power to inforn you, that $I$ have again conferred with the poorlaw commissioners, on the subject of the various grievances of which the surgeons employed under the poor-laws complain; and they have been pleased to make such alterations in their regulations about to be issued as will redress nearly all of them; and $I$ have a confidert hope that, in the course of a reasonable time, the whole will be removed.

From the varions communications I have had at aifferent times with the poor-law commissioners, and particularly with Mr. G. C. Lewis, I am convinced that the members of the medical profession have firm friends in them, and I roly as much on their kindly feelings as on the justice of the claims which may be placed before them.

A careful inquiry has satisfied me that the total sum paid by the different boards of guardians, to all the practitioners in England and $W$ ales in charge of the poor, is not half what it ought to be, according to any of the computations or calculations which have been made, either by doctors or assistant poor-law commissioners, on the subject; and if the guardians of the poor will not consent to give a reasonable remumeration to a medical man for his attendance on the poor, the public must not expect them to be fiirly or honestly taken care of:

I beg you will have the goodness to communicate the contents of this note to the gentlemen who favoured the vice-presidents, and myself, with their company at the college; and that you will believe me to be, most truly yours,

T. Howell, Esq., Clapton."

G. J. Guthrie, President, R.C.S.

\section{PETITION ON POOR-LAW MEDICAL RELIEF.}

The following form of petition on the subject of poor-law medica! relief has been adopted by the Worcester Council of the Provincial Association. As the season for active exertion in this important matter is rapidly approaching, we would earnestly entreat the local councils of the Association to prepare petitions of a similar nature for presentation to Parliament.

A well sustained effort at the present moment cannot fail to produce beneficial results :-

That the bill, which your petitioners expect will speedily come under the consideration of Parliament, for the further amendment of the laws relating to the relief of the poor, will afford an opportunity for improving the present imperfect and unsatisfactory provision of medical relief.

That in the year 1838, a committee of your Honourable House examined several medical practitioners, who were unanimous in suggesting certain amendments of the present system, several of which were approved of and recommended by that committee, and have since been agreed to, although not adopted by the poor-law commissioners.

Your petitioners therefore humbly pray that provisions to secure the general adoption of these measures may be introduced into the said bill; and, in particular :-

First,--That a medical director may be appointed to superintend all matters relating to the medical relief of the poor, to which depart. ment his whole time and attention may be devoted. 